\title{
Influence of Lanthanum and Barium on the Electrochemical Properties of Grid Alloys in Lead-Acid Energy Storage Batteries
}

\author{
Shaoqiang Yang ${ }^{1}$, Xianyu Cai ${ }^{2}$, Ruhong $\mathrm{Li}^{1}$, Baofeng Yang ${ }^{1,2}$, Xinguo Hu ${ }^{1}$, Changsong Dai ${ }^{1, *}$ \\ ${ }^{1}$ MIIT Key Laboratory of Critical Materials Technology for New Energy Conversion and Storage, \\ School of Chemistry and Chemical Engineering, Harbin Institute of Technology, Harbin, Heilongjiang, \\ 150001, PR China, E-mail: changsd@ hit.edu.cn; \\ ${ }^{2}$ Key Laboratory of Electrochemical Energy Storage Technology Enterprises of Jiangsu, Shoto Group \\ Co. Ltd. Taizhou, Jiangsu, 225300, PR China \\ *E-mail: changsd@ hit.edu.cn
}

doi: $10.20964 / 2018.11 .88$

Received: 20 July 2018 / Accepted: 5 September 2018 / Published: 1 October 2018

\begin{abstract}
Lead acid battery is the most preferential option for energy storage application because of its mature manufacturing technology, reliability and high safety. Nonetheless, a negative trait is that the leadcalcium $(\mathrm{Pb}-\mathrm{Ca})$ alloy may suffer severe corrosion as a result of long-term depth discharge. Herein, corrosion resistance property has been implemented by cyclic voltammetry (CV) approach and the concentration of $\mathrm{Pb}^{2+}$ in the mixture solution (acetic acid, nitric acid and hydrogen peroxide) are measured for the first time by inductively coupled plasma atomic emission spectrometry (ICP-AES) after corrosion test. The addition of the lanthanum (La) and barium $(\mathrm{Ba})$ can improve the corrosion resistance of $\mathrm{Pb}-\mathrm{Ca}-\mathrm{Sn}-\mathrm{Al}$ alloy in sulfuric acid electrolyte. Furthermore, the outstandingly high conductivity of the oxidation film on aforementioned alloy electrode is achieved because the growth of $\mathrm{PbO}$ in the oxidation film is inhibited by the $\mathrm{La}$ or $\mathrm{Ba}$ in $\mathrm{Pb}-\mathrm{Ca}-\mathrm{Sn}-\mathrm{Al}$ alloy. Meanwhile, the addition of La or Ba can improve oxygen evolution performance of alloy electrodes in sulfuric acid electrolyte.
\end{abstract}

Keywords: Lead alloys; Anodic films; Lead acid battery; Energy storage application

\section{FULL TEXT}

(C) 2018 The Authors. Published by ESG (www.electrochemsci.org). This article is an open access article distributed under the terms and conditions of the Creative Commons Attribution license (http://creativecommons.org/licenses/by/4.0/). 